\title{
The Morpho-Phonology-Semantics Interface in Modern Standard Arabic
}

\author{
Cherif TEIMI \\ Department of English, Faculty of Languages and Arts, Ibn Tofail University, Kenitra, Morocco \\ cherif.teimi@uit.ac.ma
}

DOI: http://doi.org/ 10.36892/ijlls.v3i4.724

\begin{tabular}{|c|c|}
\hline $\begin{array}{l}\text { Received: } \\
\text { 12/10/2021 }\end{array}$ & $\begin{array}{l}\text { Abstract } \\
\text { The issue of the interface between linguistic components has got much interest }\end{array}$ \\
\hline $\begin{array}{l}\text { Accepted: } \\
\text { 29/11/2021 }\end{array}$ & $\begin{array}{l}\text { in contemporary linguistics especially after the advancements that took place in } \\
\text { the discipline of Conceptual Semantics. In essence, linguistics components have }\end{array}$ \\
\hline $\begin{array}{l}\text { Keywords: } \\
\text { Interface, } \\
\text { Conceptual } \\
\text { Semantics, morpho- } \\
\text { phonology, } \\
\text { intentions, } \\
\text { causativisation, } \\
\text { intransitive verbs, } \\
\text { non-causatives, anti- } \\
\text { causatives. }\end{array}$ & $\begin{array}{l}\text { all been considered to be equal in terms of deriving meaning. In this article, the } \\
\text { researcher scrutinized how the component of morpho-phonology interfaces with } \\
\text { semantics. This aim was achieved through the analysis of intransitive verbs in } \\
\text { Modern Standard Arabic (MSA, henceforth). It was found that intransitive } \\
\text { verbs serve well in terms of demonstrating the interface between morpho- } \\
\text { phonology and semantics. The morphological and phonological alternations of } \\
\text { intransitive verbs result in changes in meaning. Cognition has a central role in } \\
\text { generating causative verbs from intransitive ones. }\end{array}$ \\
\hline
\end{tabular}

\section{INTRODUCTION}

In his (1997) book, Jackendoff presumes that linguistic components bear equal statuses and constitute a parallel architecture. These linguistic components interface with one another to derive meaning (see also Jackendoff 2002 and 2007). In this framework, we will deal with the interface between morpho-phonology and semantics. We will see how these components interface with each other and what governs this operation. In other words, we shall see if lexical items and their morphological alternations derive meaning or not. Here, we will treat the topic of the interface between morpho-phonology and semantics through the analysis of intransitive verbs in MSA; we will compare them to the English intransitive verbs, when necessary. In this analysis, we will also see how intentionality governs the operation of generating causative verbs from intransitive verbs. In other words, we will clarify why some intransitive verbs in Arabic change into transitive verbs while others cannot.

Intransitive verbs are distinguished into two subclasses. One subclass contains unergative verbs. The verbs of this type express intentional/ volitional actions e.g., dance, run, walk, smile, sing, etc. Verbs of this type in MSA are raqasa (dance), rahala (depart), and jaa?a (come), etc. The other subclass of intransitive verbs contains unaccusative verbs. This type of verbs denotes non-intentional/ non-volitional actions e.g., fall, melt, burn, etc. Equivalents to them in MSA are saqata (fall), marida (get sick), maata (die), Pinhaara (collapse), etc. In the following sections, we see how morpho-phonology interfaces with semantics throughout analyzing these types of verbs. To be organized and concise, we will limit ourselves to studying few morpho-phonological phenomena that exhibit the interface between morpho- 
phonology and semantics; syntax is also involved in this process since syntactic categories and elements are generated by morphological alternations and processes. Here, we will focus on phenomena like inflection, derivation, causativization, and anticausativization, etc. in MSA. First, we deal with inflection.

2. Inflection as a morphological generator of meaning

2.1. Distinguishing Inflection from Derivation

There is a considerable debate about the difference between inflection and derivation (e.g., Bauer 2004, and Kornai 2020). The two concepts are usually mixed up. However, Anderson (1982 p: 587) provides a clear-cut definition for inflection as he points out that "inflectional morphology is what is relevant to the syntax" (cited in Bauer 2004 p: 2). Inflection concerns changes that words undergo in terms of their syntactic forms without changing the part of speech of the word under the process of inflection. Alaoui, Jmila, and Afkiniche (2004 pp: 82- 85) discuss the issue of inflection and derivation in detail. For them, "inflection is a morphological process whereby affixes are added to a stem to produce a new word-form without changing the part of speech of that stem. Inflectional affixes express grammatical categories such as number, person, gender, tense, aspect, voice, case, and mood." As we see in this definition, inflection is what is relevant to syntactic changes of word forms without changing their grammatical categories. On the other hand, "derivation is a morphological process whereby affixes are added to a base to form a new lexeme; +er in the word speaker is a derivational morpheme because it transforms the word class of the word speak from a verb into a noun" (ibid). Now, it is clear that inflection is syntactic whereas derivation is morphological. Inflection is about morphological changes that a word undergoes on the level of syntax whereas derivation concerns morphological changes that a word undergoes on the level of morphology.

In the following subsection, we will deal with how morphology links to semantics via the process of inflection. That is, we discuss how can we express or change meaning via adding or changing a morpheme, etc.? As already mentioned, we analyze intransitive verbs especially in terms of expressing intentional and non-intentional actions. Also, we discuss why some intransitive verbs can be causativized while others cannot. We also consider the role of intentionality in this phenomenon.

\subsection{Inflection and the Linking of Morphology to Semantics}

Here, we will deal with intransitive verbs to see what types of them can inflect to causative, (i.e., transitive), and what governs this process. In other words, we will determine the mechanism that is responsible for the process of word formation and its meaning. Consider the examples from MSA on the table in (1).

\begin{tabular}{|c|c|}
\hline (1) Intransitive (unaccusative + unergative) & Causative (transitive) \\
\hline $\begin{array}{l}\text { a. saqata l-kitaabu. } \\
\text { fell-3ps the-book-NOM } \\
\text { "the book fell" }\end{array}$ & $\begin{array}{l}\text { a'. Pasqata khalidun l-kitaaba. } \\
\text { Made-fall-3ps Khalid-Nom the-book-ACC } \\
\text { "Khalid made the book fall" }\end{array}$ \\
\hline $\begin{array}{l}\text { b. hazina l-rrajuli. } \\
\text { grieved -3ps the-man-NOM } \\
\text { "the man grieved" }\end{array}$ & $\begin{array}{l}\text { - b'. ? } \text { ?ahzana l-rrajulu akhaahu. } \\
\text { Made sad-3ps the-man-NOM his-brother-ACC } \\
\text { "The man grieved his brother" }\end{array}$ \\
\hline $\begin{array}{l}\text { c. dakhala khalidun Pila l-maktabi. } \\
\text { entered-3ps Khalid-NOM to-PREP the-office- } \\
\text { GEN "Khalid entered into the office" }\end{array}$ & $\begin{array}{l}\text { c'. ?adkhala ahmadun khalidan Pila l-maktabi. } \\
\text { Made-enter-3ps Ahmed-MON to-PREP the-office- } \\
\text { GEN } \\
\text { "Ahmed made/forced/enabled Khalid to enter into }\end{array}$ \\
\hline
\end{tabular}




\begin{tabular}{|c|c|}
\hline & the office" \\
\hline $\begin{array}{l}\text { d. kharaja khalidul mina l-maktabi. } \\
\text { went-out-3ps Khalid-NOM from-PRE the-office- } \\
\text { GEN } \\
\text { "Khalid went out of the office" }\end{array}$ & $\begin{array}{l}\text { d'. ? akhraja ahmadun khalidan mine l-maktabi. } \\
\text { Made-go-out-3ps Ahmed-NOM Khalid-ACC } \\
\text { from-PRE the-office-GEN } \\
\text { "Ahmed made Khalid go out of the office" }\end{array}$ \\
\hline $\begin{array}{l}\text { e. waqafa khalidun Sala l-minassati. } \\
\text { Stand-3ps Khalid-NOM on-PRE the-stage-GEN } \\
\text { "Khalid stood up on the stage" }\end{array}$ & $\begin{array}{l}\text { e'. Pawqafa ahmadun khalidan Sala l-minassati. } \\
\text { Made-stand-3ps Ahmed-NOM Khalid-ACC on- } \\
\text { PRE the-stage-GEN } \\
\text { "Ahmed made Khalid stand up on the stage" }\end{array}$ \\
\hline $\begin{array}{l}\text { f. rahala l-nnassu Pila l-muxayyami. } \\
\text { departed-3pp the-people-NOM to-PRE the-camp- } \\
\text { GEN } \\
\text { "People departed to the camp" }\end{array}$ & $\begin{array}{l}\text { f'. rahhalat-i l-ssulutaatu l-nnassa Pila } l \text { - } \\
\text { muxayyami. } \\
\text { Made-depart-3pp the authorities-NOM the-people- } \\
\text { ACC to-PRE the-camp-GEN } \\
\text { "The authorities made people depart to the camp" }\end{array}$ \\
\hline $\begin{array}{l}\text { g. raqasa khalidun. } \\
\text { Danced-3ps Khalid-NOM } \\
\text { "Khalid danced" }\end{array}$ & $\begin{array}{l}\text { g'. raqqasa ahmadun khalidan. } \\
\text { Made-dance-3ps Ahmed-NOM Khalid-ACC } \\
\text { "Ahmed made Khalid dance" }\end{array}$ \\
\hline $\begin{array}{l}\text { h. naama l-tiflu. } \\
\text { slept-3ps the-child-NOM } \\
\text { "the child slept" }\end{array}$ & $\begin{array}{l}\text { h'. nawwamat-i l-mar?atu l-tifla. } \\
\text { Made-sleep-3ps the-mother-NOM the-child-ACC } \\
\text { "The mother made the child sleep" }\end{array}$ \\
\hline
\end{tabular}

Verbs in sentences (1a) and (1b) are unaccusative. They are unaccusative since the event of the falling of the book expressed by the verb saqata (fall) and the state of the sadness expressed by the verb hazina (grieve) are non-volitional. Verbs in sentences (1c), (1d), and (1e) are unergative because they express the actions of entering into the office, going out of the office, and standing on the stage that are volitional. Therefore, the verbs dakhala (enter), kharaja (go out), and waqafa (stand up) to be unergative.

Now, we consider the causative form of these verbs. Adding the morpheme $?^{1}$ to the initial position of these verbs changes the meaning from expressing self-initiated actions to expressing causative actions, i.e., actions that are performed by extrinsic actors, causers. The prefix $? a$ changes the intransitive verbs in ( $1 \mathrm{a}, \mathrm{b}, \mathrm{c}, \mathrm{d}$, and e) into transitive forms (1a', b', c', d' \& e') which bear causativization. Therefore, the conceptual structures of these sentences are linked to their morphological structures. Consider (2) and (3).

\begin{tabular}{|c|c|c|c|c|}
\hline (2) & saqata (fall & & \multicolumn{2}{|c|}{ hazina (grieve) } \\
\hline Morphological Template & Cvevev & & crever & \\
\hline Syntactic Structure & V Subj & & V Subj & \\
\hline Conceptual Structure & EVENT & UNDERGOER & EVENT & EXPERIENCER \\
\hline
\end{tabular}

\begin{tabular}{|c|c|c|}
\hline (3) & dakhala (enter) & kharaja (go out) \\
\hline Morphological Template & Cvevev & cvevev \\
\hline Syntactic Structure & V Subj & V Subj \\
\hline Conceptual Structure & AGENT & AGENT \\
\hline
\end{tabular}

\footnotetext{
${ }^{1}$ The phoneme $/ P /$ is the glottal stop (hamza) in Arabic. Attaching ' $a$ ', ' $i$ ' or ' $o$ ' to the glottal stop produce the vowels 'a', 'i' or 'o', respectively.
} 
The intransitive verbs with certain morphological forms reveal the meaning of self-initiated events and actions as is notated in (4).

(4) $[$ intra V] $\longrightarrow$ INTRANSIC ACTION

Also, adding the prefix $P a$ to the intransitive verbs (for both unaccusative and unergative verbs) in (1a-e) changes the verbs from expressing self-initiated events/actions to expressing causative actions; actions performed by extrinsic actors as expressed in (1a'- e'). Thus, the morpheme of transitivity, $? a$, in the morphological structure bears the meaning of causativization in the conceptual structure, the notation is the following:

(5) pref (?a) + [intr V] $\rightarrow$ EXTRINSIC ACTION

The morphological, syntactic, and thematic representations correspond to one another as follows:

\begin{tabular}{llll}
\hline (6) & Pasqata (make fall) & \multicolumn{2}{l}{ Pahzana (make sad) } \\
\hline Morphological Template & Cvecvev & \multicolumn{2}{c}{ cvecvev } \\
Syntactic Structure & V Subj Obj & V Subj Obj \\
Conceptual Structure & ACT AGENT PATIENT & ACT AGENT PATIENT \\
\hline
\end{tabular}

However, the first inference we make about intransitive verbs is that they express selfinitiated events (intrinsic actions); the actor is the instigator of the event. And, the causative outputs of the intransitive verbs after adding the prefix ? $a$ express actions (extrinsic actions) performed necessarily by an extrinsic actor, the causer. We notate the intrinsic and extrinsic actions as follows:

(7) a. $\mathrm{X}+$ (intr. V) $\rightarrow$ INTRINSIC ACTION (self-initiated action)

b. $\mathrm{X}+$ Pref. $(\mathrm{Pa})+($ intr V) $\longrightarrow$ EXTRINSIC ACTION (causative action)

Sentences in ( $\mathrm{f}, \mathrm{g}$, and $\mathrm{h}$ ) contain verbs that are unergative which express volitional and intentional actions. Actors in these examples are the instigators of the actions; they are the entities that initiate the actions. However, geminating the second phoneme in each verb in these sentences changes the meaning from expressing self-initiated actions to expressing causative actions (i.e., actions performed by extrinsic actors, causers) as exemplified in (1f', g' \& h'). In other words, geminating the second phoneme of the verbs in (1f, $\mathrm{g}$, and $\mathrm{h}$ ) changes them from intransitive forms which express self-initiated actions to transitive forms (1f', g' \& h') which express causative actions, actions performed by extrinsic actors. The case of the examples (1f, g, and h) is slightly similar to the one of (1a-e). Both morphological changes give us the same result. The only difference is that we add the prefix $(? a)$ in the former examples and geminate the second phoneme in the latter examples. Here, there is a direct correspondence between morphology and semantics. Changing the morphology of the verbs above results in changing their semantic meanings.

\begin{tabular}{|c|c|c|}
\hline (8) & Padkhala (make enter) & Pakhraja (expel) \\
\hline Morphological Template & Cvecrev & cvecvev \\
\hline Syntactic Structure & Subj & V Subj \\
\hline Conceptual Structure & $\begin{array}{l}\text { ACT AGENT PATIENT/ } \\
\text { BENEFICIARY }\end{array}$ & $\begin{array}{l}\text { ACT AGENT PATIENT/ } \\
\text { BENEFICIARY }\end{array}$ \\
\hline
\end{tabular}

(9) a. Adding the prefix (?a)

cvevev $\rightarrow($ ?a $)+\mathrm{ccvev}$ 
saqata $\rightarrow$ ?a-sqata (fall; cause to fall)

dakhala $->$ ?a-dkhala (enter; make/ cause to enter)

kharaja -> ?a-khraja (go out; expel)

b. Gemination

cvevev -> cvecacv

raqasa $\rightarrow$ raqqasa (dance; make dance)

rahala $\rightarrow>$ rahhala (leave; cause/ force to leave)

Attaching the prefix $(? a)$ and geminating the second consonant in the morphological template of an intransitive verb result in changing the meaning from expressing pure events (events happening by themselves) or self-initiated action to expressing causative actions. This mere change in the morphology of the verbs causes big changes in meaning and therefore brings about changes in the conceptual structure of the sentences. Consider the thematic representations of the following sentences as examples.

\begin{tabular}{lcclcc}
\hline (10) & a. saqata & l-kitaabu. & b. & Pasqata & khalidun \\
& fell-3ps & the-book-NOM & $\begin{array}{l}\text { Made-fall-3ps } \\
\text { the-book-ACC }\end{array}$ & Khalid-Nom \\
& V & Subj & V & Subj & Obj \\
Syntactic Structure & EVENT & Undergoer & ACT & Agent & Undergoer \\
Conceptual Structure & & & & &
\end{tabular}

The conceptual structures of the sentences (1a) and (1a')/ (10a \& b) will be (11a) and (11b): (11a)

[Situation PAST [Event $\left(\begin{array}{ll}\text { BOOK } \\ \text { [Property INANIMATE] ] } \\ \text { Object } \\ \text { DEF }\end{array}\right]$

(11b)

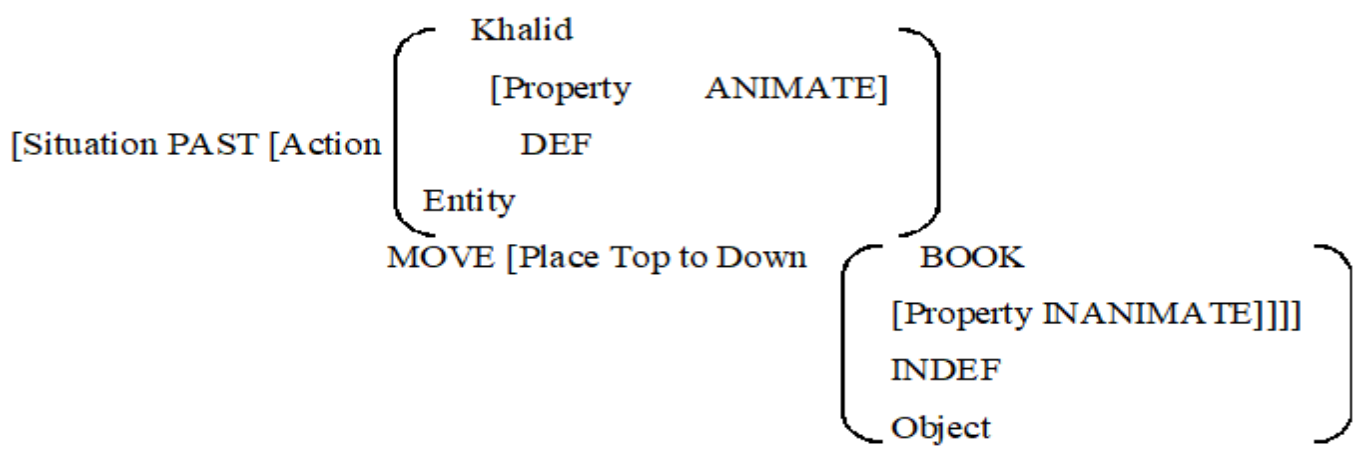

3. Non-causative Intransitive Verbs

As we just mentioned, some intransitive verbs in MSA cannot be changed into transitive forms and therefore they cannot become causative. Now, analyze non-causative intransitive verbs to see why they cannot be causativized. These verbs are non-causative in the sense that they cannot become causative whatsoever. Their roots cannot be inflected to form causative counterparts. Why? Consider the examples in (12).

(12) a. harwala l-rrajul-u

Jogged-3ps the-man-MON 
"The man jogged"

b. ghaadara khalid-un

Left-3ps Khalid-MON

"Khalid left"

c. bar'amat-i l-zzahrat- $u$

sprouted-3ps-Fem the-flower-NOM

"The flower sprouted"

d. 'dmahalla l-ssahaab-u

Decayed-3ps the-clouds-NOM

"The clouds decayed"

Sentences in (12) contain intransitive verbs that take intrinsic actors as their arguments. The events expressed in these sentences are either self-initiated actions as in $(12 \mathrm{a}, \mathrm{b}$ \& c); the verbs 'harwala' [jog] and 'ghaadara' [leave] are unergative verbs that express intentional actions. These two verbs neither can express causative action nor inflect to generate causative forms. The Sentence in (12c) expresses a pure passive event; the actor in this sentence is the entity affected by the event. It is patient in the conceptual structure. The verbs in (12) cannot become causative. Look at the examples in (13).

(13) a. ?? harwalt-u l-rrajul-a

Made-run-I-1ps the-man-ACC

"I made the man jog"

b. ?? ghaddart-u khalid-an

Cause-to-leave-I-1ps Khalid-ACC

"I caused Khalid to leave"

c. ?? bar'amt-u l-zzahrat-a

I-sprouted- $1^{\text {st }}$ ps the-flower-ACC

"?? I sprouted the flower"

d. ?? d'mahalt-u l-ssahaab-a

I-made-decay-1ps the-clouds-ACC

"?? I made the clouds decay"

We notice here that some verbs of the two sub-classes of intransitive verbs in MSA (i.e., unergative and unaccusative verbs) cannot change to causative forms. The question is why?

As is clear from the examples in (12) and the semantically non-acceptable examples in (13), verbs in these examples express either pure events (something happening by itself) as in (12d) or self-initiated actions as expressed by sentences that contain unergative verbs as in $(12 \mathrm{a}$ and $\mathrm{b})$. Actions here are instigated by volitional intentional actors, agents; they cannot become causative because they do not require extrinsic actors or causers. They require, instead, intrinsic actors. The example in (12c) expresses a self-initiated event but cannot be intentional; the verb 'bar'ama' [sprout] here expresses a merely natural growth of a flower. Thus, MSA has, in addition to anti-causative verbs, non-causative verbs. This latter type, unlike the former, cannot inflect to form causative counterparts. Now, we discuss another type of verbs called Anti-causative verbs ${ }^{2}$.

4. Anti-causatives in MSA and English

\footnotetext{
${ }^{2}$ The difference between non-causative and anti-causative verbs is that the first type is lexical whereas the second is syntactic (i.e. we get it via the process of inflection).
} 
Anti-causative verbs in English and other languages have been given much concern in the discipline of the morphology-semantics interface (for example, Alexiadou, Anagnostopoulou, and Schäfer 2005; Koontz-Garboden 2009; Levin et al., 1995; Rappaport Hovav \& Levin, 1998; Hespelmath 2002 among many others). In this subsection, I will discuss this class of verbs in MSA and make some comparisons with the English ones when necessary.

Anti-causative verbs, also called inchoative verbs, describe change of state that an entity undergoes (Tatevosov, 2013). In this subsection, I will examine anticausatives in MSA in regards to some previous studies conducted on this type of verbs. First and foremost, and based on the conceptual/ semantic perspective, we do not agree with Horvath and Siloni (2013) who claim that "there is absolutely no Cause(r) involved in anticausatives". Apart from this, their arguments do not support their conclusion! They face some counterexamples from other languages like MSA. Here I ask a simple question. Does anti-causativization reveal that there is no causation in the event expressed by a sentence containing an anticausative verb or there is just a sort of back-grounding of the causer-agent as with the case of passivization? Let us consider the following examples from MSA and English.

(14) a. Pinkassar-a l-ka?ss-u

Broke-3ps the-cup-NOM

"The cup broke"

b. Pinfatah-a l-baab-u

Opened-3ps the-door-NOM

"The door opened"

c. Pinjaraf-a l-turaab-u

Drifted-3ps the-soil-NOM

"The soil drifted"

(15) a. The window broke.

b. The door opened.

c. The ice melted.

Unlike English ${ }^{3}$, MSA overtly marks anticausatives. As is clear from the MSA examples in (14) and the English ones in (15), MSA morphologically marks anticausativization by adding a morpheme to the beginning of the verb. Pinkasara (broke), Pinfataha (opened), and Pinjarafa (drifted) in (14) are morphologically derived from their causative counterparts kasara (break), fataha (open) and jarafa (drift), respectively. But, for the English examples in (15), verbs are semantically, but not morphologically, marked for anti-causativization. However, both MSA and English examples in (14) and (15) express change of state without an overt causer. The causer is back-grounded in our conceptualization. This is counterevidence to the aforementioned claim of Horvath and Siloni (2013 p: 2). Anticausatives, like passives, involve covert causers even though syntax does not exhibit that. Events expressed in (14) and (15) cannot take place without external forces; either animate, inanimate or natural forces like sun and wind.

Anticausatives, however, denote a lack of causation and outside help or intervention, especially when used with modifiers. The modifier by itself and its equivalent 'min tilqaa?i nafsih' in MSA show that there is no outside intervention, especially human intervention.

(16) a. Pinfajara l-barmiil-u min tilqaa?i nafsih

\footnotetext{
${ }^{3}$ Beavers and Koontz-Garboden (2012 p: 4) point out that "English (...) does not have morphological anticausativization".
} 
Exploded-3ps the-vat-NOM by itself

"The vat exploded by itself"

b. Pinfatah-a l-baab-u min tilqaa?i nafs-ih

Opened-3ps the-door-NOM by itself

"The door opened by itself"

c. tadahrajat-i lkurat-u min tilqaa?i nafsih-a

Rolled-3ps-Fem the-ball-NOM by itself

"The ball rolled by itself"

Nevertheless, other tests prove that causation exists in the so-called anticausatives. The first test is the 'did not' test (Horvath and Siloni 2013 p: 6) and the second is the 'because of' test. Let us consider the following example from MSA.

(17) a. Son: ?inkasarat-i l-naafidat-u

Boke-3ps-fem the-window-NOM

"The window broke"

Father: al-naafidat-u lam tankassir. ?anta kasar-ta-h-a

The-window-NOM didn't break -you-1ps broke-SING-FEM it

"The window did not break. You broke it!"

As we notice in (17), with anti-causative cases, we tend to avoid (sometimes to mislead) mentioning the reason behind the event. There is implicit causation that does not appear in syntax. For causation to be overtly expressed, a sentence must contain a two-argument predicate. A sentence like John broke the window is causative and it contains the predicate break and its two arguments John and window. But, for anti-causatives, the predicate holds one argument only; the window broke. The causer is not expressed in the syntax; yet, it may take place in our conceptualization. This is about the 'did not' test, now we turn to the 'because of' test. Take the examples in (18).

(18) a. Pinfajar-a l-barmii-lu bi-sababi l-hararat-i.

Exploded-3ps the-vat-NOM because-of the-heat-GEN

"The vat exploded because of the heat"

b. Pinjaraf-a l-turaab-u bi-sababi l-Pamtaar-i.

Drifted-3ps the-soil-NOM because-of the-rain-GEN

"The soil drifted because of rain"

c. Pinkasara-t-i l-naafidat-u bi-sababi l-riih-i.

Broke-3ps the-window-NOM because-of the-wind-GEN.

"The window broke because of wind"

d. Pinfatah-a lbaab-u bi-sababi l-riih-i.

Opened-3ps the-door-NOM because-of the-wind-GEN.

"The door opened because of the wind"

Undoubtedly, events expressed by anticausatives usually take place because of an external force even though they "[anticausatives] lack an implicit external argument due to a lexical process of detransitivization that creates an intransitive entry from the transitive one" (Alexiadou, et al., 2005, p. 3). Nevertheless, syntax and morphology do not exhibit this external force, the causer. In syntax, the subject links to the role Patient but not to the role agent; and in morphology, there is a process of detransitivization that changes the verb from transitive form (i.e. causative) to intransitive form (i.e. anticausative); thus, the sentence with 
an anti-causative verb does not overtly show causation. In (18), the 'because of' expression substitutes the subject-agent argument. (18a-c) can be paraphrased as (19a-c).

(19) a. fajjara-t-i l-hararat-u l-barmiil-a.

Exploded-3ps the-heat-NOM the-vat-ACC

"The heat exploded the vat"

b. jarafa-t-i l-?amtaar-u l-turaab-a.

Drifted-3ps the-rain-NOM the-soil-ACC

"The rain drifted the soil"

c. kasara-t-i lriih-u l-naafidat-a.

Broke-3ps the-wind-NOM the-window-ACC

"The wind broke the window"

As has been noted, anti-causativization does not entail that there is no causation involved in the event, as Horvath and Siloni (2013) claim, but rather there is covert causation that does not appear in syntax. Anti-causative verbs are monadic verbs that require only one argument. That is, the sentence with an anti-causative verb does not contain an object-patient argument; the argument over which causation takes place. Thus, the so-called anticausatives are named so due to a syntactic reason (i.e. they do not have a causer-argument in their predicate structure). However, events expressed by some anti-causative verbs do lack outside interventions or extrinsic causers. Apart from this, anticausatives, like passives, tend to avoid mentioning the real agent behind the event. This is so either because we tend to escape from responsibility or the causer-agent is unworthy to be mentioned.

5. Conclusion

All things considered, intransitive verbs serve well in terms of demonstrating the interface between morpho-phonology and semantics. The morphological and phonological alternations of intransitive verbs result in changes in meaning. For this reason, as we saw, we get different conceptual structures. Moreover, cognition has a central role in generating causative verbs from intransitive ones. Preventing the generation of a causative verb from an intransitive verb is not due to morphological reasons but conceptual ones. It has to do with our cognitive perception of the world. The verb /bar'ama/ (sprout) in (13c) cannot be causativized not for morphological blockage (nothing can prevent us from saying [?? ?ana bar'am-tu l-zzahrat-a] (??I sprouted the flower)). But conceptually that is unacceptable! The process of sprouting is intrinsically instigated. It cannot have an outside causer. Thus, we can infer that our cognition governs the production of morphological items.

References

Alaoui, A., Jmila, M. and Afkinich, T. (2004) Basics in Linguistics, Phonology, and Morphology. Publications of Interlaguages. Top Press. LTD.

Alexiadou, A., Anagnostopoolou, E., and Schafer, F. (2005) The Properties of Anticausatives Crosslinguitically. To appear in M. Frascarell, (ed.) Phrases of Interpretation, Berlin: Mouton. Retrieved from: http://www.philology.uoc.gr/staff/anagnostopoulou/files/a11.pdf

Bauer, L (2004) The Function of Word-Formation and the Inflection-Derivation Distinction. In Henk Aertsen; Hannay, Mike and Lyall, Rod. in Words in their Palaces. A Festchrift for J. Lachlan Mackenzie. Amsterdam: Vrije Universiteit, 283-292. Retrieved from: http://www.victoria.ac.nz/lals/about/staff/publications/Bauer-InflDeriv.pdf 
Beavers, J. \& Koontz-Garboden, A (2012) In Defence of the Reflexivization Analysis of Anticausativization. Department of Linguistics and English Language. Samuel Alexander Building, the university of Manchester, Oxford Road. Manchester, M13 9PL, United Kingdom. Retrieved from: http://fulltext.study/preview/pdf/935351.pdf

Haspelmath, M. (2002) Understanding Morphology. Oxford University Press. Inc., New York.

Horvath, J. \& Siloni, T. (2013) Anticausatives have no Cause(r): A rejoinder to Beavers \& Koontz-Garboden. Retrieved from: https://www.tau.ac.il/sites/tau.ac.il.en/files/media_server/imported/326/files/2013/0 4/LINGUA-2031-Revised-Proof3.pdf

Jackendoff, R. (2007) Language, Consciousness, Culture: Essays on Mental Structure. The MIT Press Cambridge, Massachusetts, London, England.

Jackendoff, R. (2002) Foundations of Language: Brain, Meaning, Grammar, Evolution. Oxford University Press Inc., New York.

Jackendoff, R. (1997) The Architecture of Language Faculty. The MIT Press Cambridge, Massachusetts, London, England.

Kornai, A. (2020) Semantics. Springer International Publishing, Springer Nature Switzerland AG. DOI: 10.1007/978-3-319-65645-8

Levin, B., Hovav, M. R., \& Keyser, S. J. (1995). Unaccusativity: At the syntax-lexical semantics interface (Vol. 26). MIT press. Cambridge, Massachusetts. London, England.

Rappaport Hovav, M., \& Levin, B (1998) Building verb meanings. The projection of arguments: Lexical and compositional factors, ed. by Miriam Butt and Willi Geuder, 97-134. Stanford: CSLI Publications. Retrieved from: http://www.cs.rochester.edu/u/james/Papers/Building_Verb_Meanings.pdf

Tatevosov, S. (2013) Event Structure of the Anticausative and Unaccusative in Russian. Lomonosov, Moscow State University. Retrieved from: http://otipl.philol.msu.ru/staff/people/tatevosov/iatl_tatevosov_1.2.pdf

\section{AUTHOR'S BIO}

Cherif Teimi (PH.D) is an assistant professor in English, Department of English, Faculty of Languages and Arts, Ibn Tofail University, Kenitra, Morocco. Former assistant professor at Ibn Zohr University, Agadir, Morocco. Former Lecturer in English at Jazan University, Jazan, Saudi Arabia. His research interests include Conceptual and Cognitive Semantics, and the interfaces between linguistic components. 